\title{
Contrasts in prevalence and determinants of current tobacco smoking status among adults in Indonesia as indicated by the rural-urban place of residence
}

\author{
Md. Salauddin Khan', Md. Akid Rahman', Tahera Mahnaz Meem', Umama Khan² \\ 'Statistics Discipline, Khulna University, Khulna-9208, Bangladesh \\ 2Biotechnology and Genetic Engineering Discipline, Khulna University, Khulna-9208, Bangladesh
}

\begin{abstract}
Introduction: The patterns of smoking addiction or exposure are not same in all places. This study aims to examine the determinants and patterns of current tobacco smoking (CTS) exposure among male and female adults at rural and urban places of residences.

Material and methods: Data set selected for this study covers a nationally representative sample of 8,146 respondents extracted from the Global Adult Tobacco (GATS) Survey-2011 Indonesia. The frequency distribution was used to introduce the response variable along with several independent variables with primary information. The chi-square test was executed to find the association between the study variable with different selected variables. In logistic regression, CTS exposure status of adults based on male and female with different places of residence was used as the response variable. Demographic and socioeconomic variables, health knowledge about CTS, attitude and perception of tobacco smoking (TS) restrictions were considered as predictor variables.

Results: Aged male adults (above 44 years old) were less exposure and females in all age groups were more exposure to tobacco smoking compared to reference group. Only female respondents who were living with large families of more than five members had higher risk to be exposed to CTS but females were less exposed compared to males in both rural and urban regions. Better education, higher wealth index, better health knowledge and practice of no smoking at home were associated with lower CTS exposure in all types of cases.

Conclusions: Prevention and control processes should not be neglected in public health policies. Smoking policy should be implemented and enforced by each parts of Indonesia.
\end{abstract}

KEY WORDS: binary logistic regression, Indonesia, tobacco smoking exposure, adults.

ADDRESS FOR CORRESPONDENCE: Md. Salauddin Khan, Assistant Professor, Statistics Discipline, Khulna University, Khulna-9208, Bangladesh, e-mail: salauddinstat@ku.ac.bd

\section{INTRODUCTION}

Tobacco smoking (TS) increases severe health risks and causes about eight million deaths worldwide every year $[1,2]$. TS is recognized as the sixth most common cause of death globally [3, 4]. By 2030, it is anticipated that even more people will die due to current (both daily and occasionally tobacco users) tobacco smoking (CTS), of which $80 \%$ will occur in low- and middle-income countries [5-8]. The World Health Organization (WHO) estimated in 2015 that among the 1.074 billion tobacco smokers globally, 909 million were male and 165 million female [2]. The tobacco smoking prevalence was $24.9 \%$ and predicted to be $22.8 \%$ and $20.9 \%$ in 2020 and 2025 respectively (Fig. 1) [2, 9].

Smoking is one of the world's main public health risk factors $[10,11]$ which is a socio-economic prob- 
lem as well as a burden among people of all ages $[6,12]$. It harms economic efficiency by impeding physical function and lung capacity, and also causes more frequent illness [13]. CTS causes reduced fetal growth, low birth weight, pre-term delivery, and sudden infant death in pregnant women $[14,15]$. It causes harm to non-smokers as well, by increasing health risks, especially among children under fifteen years old [16]. Although TS is a wellknown risk factor for cancer in adults, there is emerging evidence that it may also be associated with children's cancer. In South-East Asian countries (Indonesia, Thailand, Cambodia, Malaysia, Vietnam, etc.), there are about 600 million tobacco smokers, most of whom begin smoking early in life and persist through adulthood [17, 18]. The earlier people start smoking, the more likely they are to become strongly addicted to nicotine [19]. Environmental and individual factors may act to increase the likelihood of smoking among adolescents [17-21]. Other associated risks of TS include spontaneous abortion, intrauterine growth retardation, allergic sensitization, stroke, decreased pulmonary function, reduced fertility, and adverse impacts on cognition and behavior [14, 15].

Reducing tobacco consumption is not only a global health priority but also an economic, sustainable development, and human rights issue [1, 2]. Since 2012, all 12 countries in the South-East Asian region have introduced or upgraded tobacco-control policies, which has effectively reduced the prevalence of TS among both men and women. Each country needs to monitor tobacco use among adults and adolescents to understand the consumption patterns and develop adequate policy responses [9].

The recent WHO report on the Global Tobacco Epidemic 2019 found that only 1 in 3 countries globally has monitored the consumption of tobacco [1]. Public awareness of harmfulness about smoking is increasing but it is not enough to control the TS rate. If a government does not take any initiative, such as anti-smoking campaigns and/or advertisements through electronic or social media, etc. to control tobacco consumption, it is not possible to reduce smoking rates [24].

The WHO regions of America, Europe, and the Western Pacific saw smoker numbers decline in the last two decades, but in the African, Eastern Mediterranean, and South-East Asian regions, rates did not decline substantially [2]. The prevalence of smokers was highest in South-East Asia (Fig. 2) [2]. In developing countries, the tobacco consumption rate remains relatively low for adult females but could rise quickly among teenage female. The adult male smoking rate was 10 times higher than the adult female smoking rate in South-East Asia [25-28]. However, the TS rate among men has been in decline, while among women it has increased, particularly in eastern, central, and southern Europe [29, 30].

Indonesia is the fourth most populous country as well as the fifth-largest producer of tobacco leaf in the world $[5,8]$. It ranks as the world's forty-third con-

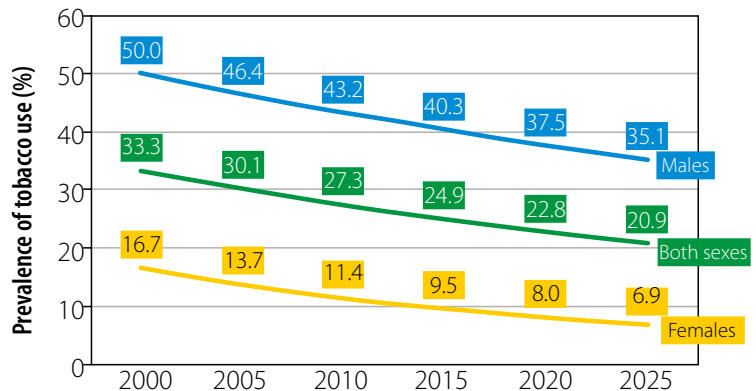

FIGURE 1. Global trends in the prevalence of tobacco use by sex [2]

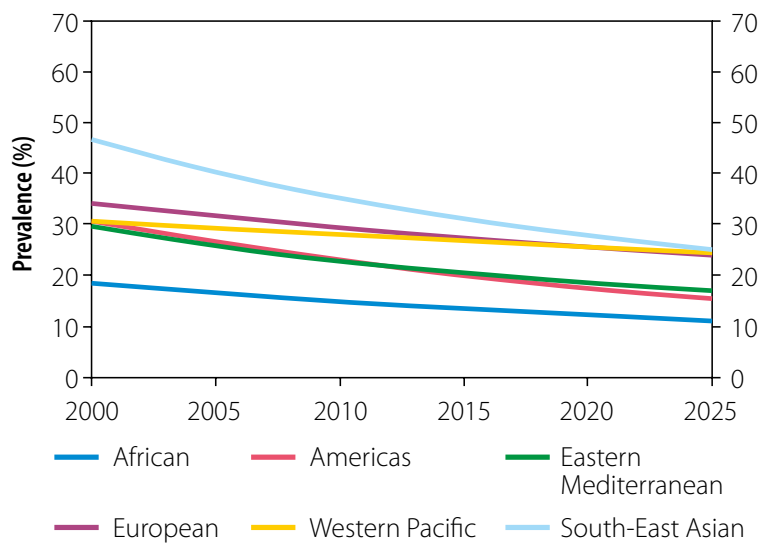

FIGURE 2. Trends in current tobacco use among people aged $\geq 15$ years [2]

sumer of cigarettes per capita, a total of 182 billion per year, and anticipates an increase in mortality due to TS $[8,30,31]$. Current tobacco smoking prevalence in Indonesia among people aged $\geq 15$ years old was $40.0 \%$ in $2000,39.0 \%$ in $2005,38.3 \%$ in 2010 , and $38.0 \%$ in 2015 and predicted that it will be $38.0 \%$ in 2025 [2]. The percentages of people aged 15 years and over who are daily smokers, occasional smokers, and non-smokers were $29.2 \%, 5.6 \%$, and $65.2 \%$ respectively [8]. About $34.8 \%$ of Indonesians are tobacco smokers, among them $67.0 \%$ of men and $2.6 \%$ of women [8]. They rank third in the number of male smokers and seventeenth for total female smokers worldwide. The TS prevalence among Indonesian men rose from $53 \%$ to $66 \%$, and among women from $1.7 \%$ to $4.2 \%$, between 1995 and 2010 [32]. From 2001 to 2010, the number of children aged between 10 and 14 years old who started smoking increased by $80 \%$, and the number who started smoking between age five and nine years quadrupled $[8,32]$. The health and welfare effects of this situation have been enormous. It is very alarming that smoking kills at least 200,000 Indonesians each year [33].

Several retrospective studies performed in Indonesia show a relationship between smoking and the risk of developing cardiovascular diseases, respiratory diseases, and cancer $[8,24]$. This study presents the current state 
of tobacco smoking, along with patterns and prevalence of tobacco consumption among Indonesian adults based on gender and place of residence. It will also identify associated factors, such as socioeconomic and demographic, along with the perception of health knowledge about smoking, that may help to raise awareness of avoiding TS among public health officials and administrators concerning both male and female adults.

\section{MATERIALS AND METHODS \\ The data and sampling}

The Global Adult Tobacco Survey (GATS) 2011, Indonesia, the latest data available, was used for this study [8]. The comprehensive methodology for the survey, including data collection, validation, and reliability assessment, was explained in the national report of the survey $[8,26,34]$. Briefly, based on a sampling frame from the Indonesian population census, the Ministry of Health nominated the Badan Pusat Statistik (BPS) and the National Institute of Health Research and Development (NIHRD) as implementing agencies. They conducted the GATS 2011 survey with four-stage sampling. In the first stage, 100 primary sampling units (PSUs) (50 from rural and 50 from urban areas) were selected according to probability proportional to size (PPS). In the second stage, a group of census blocks (CBs) in a sub-district were selected in the same type of area (urban/rural) considered as secondary sampling units (SSU) and a random sample of three SSUs was selected using the PPS sampling technique with the measure of size $(\mathrm{MoS})$ depending on the total number of households in each CB and then updated the list of population census households in the selected CBs. In the third stage, the listed households of a selected SSU household were chosen systematically (an average of 30 households to get equal male and female households). In the fourth or final stage, one respondent, randomly chosen from all the eligible persons in a selected household, participated in the survey [8]. The process of selecting respondents in the survey, GATS 2011, Indonesia was as follows:

$\mathrm{PSU} \rightarrow$ Census block $\rightarrow$ Households $\rightarrow$ Respondent (CBs)

The sample was formatted with 8581 non-institutional households covering $95.4 \%$ of the total population from all administrative areas. Eligible persons from 8581 (97.4\%) households and 8305 (96.8\%) individuals completed the interview. The number of eligible persons in urban areas (4238) was slightly lower than that in rural areas (4343) [8]. However, based on the literature, this research extracted 12 variables from 294 variables, and each variable contained 8146 respondents after removing missing values from 8305 respondents. The dataset is available at the following link: https://nccd.cdc.gov/ GTSSDataSurveyResources/Ancillary/DataReports. $\operatorname{aspx} ? \mathrm{CAID}=2$.

\section{Data collection}

Household and individual questionnaires were used by GATS for the tobacco survey. These were formulated based on core and optional questions. BPS, with counseling from local agencies (NIHRD, $\mathrm{MOH}$ ) and international collaborators, such as the Southeast Asia Regional Office and the United States Centers for Disease Control and Prevention (CDC) surveyed with financial support from Bloomberg Philanthropies. An electronic system (handheld computer) facilitated the complex skip pattern employed in this survey. During the data collection, some inbuilt validity checking on questionnaires was performed. The main steps in quality control involved version checking for household and individual questionnaires, skipping patterns, and validation checking, and checking for date and time. The data were suitably weighted to improve the representation of the size, distribution, and characteristics of the population. From design weight, household and individual response rates of the weights were derived. The whole procedure was derived from the GATS sample design manual and sample weight manual $[8,14,26]$.

\section{Data analysis tools}

Data were analyzed using SPSS version 25.0 (SPSS Inv., Chicago, IL). The frequency distribution was used to introduce the response variable along with several predictor variables. The chi-square test was executed to find the association between the study variable and selected predictor variables. Binary logistic regression determined the CTS exposure status of four separate models concerning gender and places of residence (rural and urban).

\section{The dependent and predictor variables}

We defined current tobacco smoking (CTS) as the response variable. CTS refers to both daily and occasionally tobacco users [8]. Depending on the nature of supporting data and the literature on TS exposure, our selected predictor variables were: age, gender, household members, residence, education level, wealth index, general and specific health knowledge about CTS exposure, attitude about CTS at home and workplace, and perception of smoking restrictions in some places. Detailed descriptions of the variables and their coding are given in Table 1.

\section{Statistical methods}

The analysis was segmented into three parts. The univariate analysis represented the frequency distribution of several variables and it computed the prevalence of CTS exposure at four settings (model A: male; model B: female; model C: rural; model D: urban). To obtain the prevalence of CTS exposure for various categories of the selected variables, bivariate analyses with cross-tabulations were performed. Pearson's $\chi^{2}$ test was used to identify significant 
TABLE 1. Variables for the study and their coding for analysis

\begin{tabular}{|c|c|c|}
\hline \multicolumn{3}{|c|}{ Response variable: Current tobacco smoking (CTS) exposure } \\
\hline Variable name & Question asked in the survey & Coding for analysis \\
\hline Current tobacco smoking & $\begin{array}{l}\text { Does this person currently smoke tobacco } \\
\text { (daily or occasionally) including cigarettes, } \\
\text { hand-rolled cigarettes, pipes and cigars? } \\
\text { Options: } 1=\text { yes; } 2=\text { no; } 7=\text { don't know; } \\
\quad 9=\text { refused }\end{array}$ & $\begin{array}{c}0=\text { no (option } 2 \text { and option } 7) \\
1=\text { yes (option } 1 \text { ) }\end{array}$ \\
\hline \multicolumn{3}{|l|}{ Selected variables as predictors } \\
\hline Age in years & How old were you? Open-ended question & $15-24 ; 25-44 ; 45-59 ; 60+$ \\
\hline Gender & Record gender from observation & $1=$ male $; 2$ female \\
\hline No. of household members & $\begin{array}{l}\text { In total how many persons live in this } \\
\text { household? Open-ended question }\end{array}$ & $\begin{array}{c}1=1-2 ; 2=3-4 ; 3=5-9 \\
4=10+\end{array}$ \\
\hline Residence & What is the place of residence? & $1=$ urban; $2=$ rural \\
\hline Education level & $\begin{array}{l}\text { Highest level of education? } 1 \text { = no formal } \\
\text { education; } 2 \text { = less than primary school } \\
\text { completed; } 3=\text { primary school completed; } \\
4 \text { = less than secondary school completed; } \\
5 \text { = secondary school completed; } 6 \text { = high } \\
\text { school completed; } 7=\text { college or university } \\
\text { completed; } 8=\text { post graduate degree } \\
\text { completed; } 77=\text { don't know; } 99=\text { refused }\end{array}$ & $\begin{array}{l}1=\text { no formal education } \\
\quad \text { (options } 1 \text { and } 77) ; \\
2=\text { less than primary; } \\
3=\text { primary completed; } \\
4=\text { less than secondary; } \\
5=\text { secondary and above } \\
\text { (options } 5 \text { to } 8 \text { ) }\end{array}$ \\
\hline Wealth index & $\begin{array}{c}\text { Household or any person in the household } \\
\text { has: } \mathrm{a}=\text { electricity, } \mathrm{b}=\text { flush toilet, } \mathrm{c}=\text { fixed } \\
\text { telephone, } \mathrm{d}=\text { cell phone, } \mathrm{e}=\text { television, } \\
\mathrm{f}=\text { radio, } \mathrm{g}=\text { refrigerator, } \mathrm{h}=\mathrm{car}, \mathrm{i}=\text { motorcycle, } \\
\mathrm{j}=\text { washing machine, } \mathrm{k}=\text { bicycle, } \\
\mathrm{I}=\text { sewing machine, } \mathrm{m}=\text { wardrobe, } \mathrm{n}=\text { table, } \\
\mathrm{o}=\text { bed or cot, } \mathrm{p}=\text { chair, } \mathrm{q}=\text { watch tv }\end{array}$ & $\begin{array}{l}1^{\text {st }} \text { quintile: lowest; } \\
2^{\text {nd }} \text { quintile: low; } \\
3^{\text {rd }} \text { quintile: middle; } \\
4^{\text {th }} \text { quintile: high; } \\
5^{\text {th }} \text { quintile: highest }\end{array}$ \\
\hline $\begin{array}{l}\text { General health knowledge } \\
\text { about exposure of tobacco } \\
\text { smoking (ETS) }\end{array}$ & $\begin{array}{l}\text { Based on what you know or believe, does ETS } \\
\text { cause serious illness in non-smokers? } \\
1=\text { yes; } 2=\text { no; } 7=\text { don't know }\end{array}$ & $\begin{array}{c}1=\text { yes (option } 1) \\
2=\text { no (option } 2 \text { and } 7 \text { ) }\end{array}$ \\
\hline $\begin{array}{l}\text { Specific health knowledge } \\
\text { about ETS exposure }\end{array}$ & $\begin{array}{l}\text { Based on what you know or believe does ETS } \\
\text { cause any of the following: } a=\text { heart disease } \\
\text { in adults? } b=\text { lung cancer in adults? c = lung } \\
\text { illness in children? } d=\text { bone loss in adults? } \\
\text { e- bladder cancer in adults? } \mathrm{f}=\text { COPD in adults? } \\
\text { For all six type of questions: } \\
1 \text { = yes; } 2 \text { = no; } 7 \text { = don't know }\end{array}$ & $\begin{array}{c}1 \text { = no knowledge (answer } \\
\text { no questions correctly); } \\
2=\text { some knowledge (answer any one } \\
\text { or two questions correctly); } \\
3=\text { good knowledge (answer } \\
\text { all questions correctly) }\end{array}$ \\
\hline Smoking policy (at home) & $\begin{array}{l}\text { Smoking policy inside your home? Options: } \\
1 \text { = allowed; } 2=\text { not allowed, but exception; } \\
3 \text { = never allowed; } 4 \text { = no rules; } 7=\text { don't know }\end{array}$ & $\begin{array}{l}1 \text { = allowed (option } 1 \text { and } 2) \\
2=\text { not allowed (option } 3 \text { ); } \\
3 \text { = no rules (option } 4 \text { and } 7 \text { ) }\end{array}$ \\
\hline Smoking policy (at workplace) & $\begin{array}{l}\text { Indoor smoking policy where you work? } \\
\text { Options: } 1=\text { allowed anywhere; } 2=\text { allowed } \\
\text { only in some indoor areas; } 3=\text { not allowed } \\
\text { in any indoor areas; } 4=\text { there is no policy; } \\
\qquad 7=\text { don't know }\end{array}$ & $\begin{array}{c}1=\text { smoking allowed (option } 1 \text { and } 2 \text { ); } \\
2=\text { not allowed (option } 3 \text { ); } \\
3=\text { no rules (option } 4 \text { and } 7 \text { ) }\end{array}$ \\
\hline Working status & $\begin{array}{l}\text { Which of the following best describes your } \\
\text { 'main' work status over the past } 12 \text { months? } \\
\text { options: } 1 \text { = Govt. employee; } 2=\text { private job } \\
\text { holder; } 3=\text { student; } 4=\text { retired; } 5=\text { unemployed; } \\
6=\text { homemaker; } 7=\text { don't know }\end{array}$ & $\begin{array}{c}1 \text { = employed (option } 1 \text { and } 2 \text { ); } \\
2 \text { = business holder (option 6); } \\
3=\text { student and other unemployed } \\
\text { (option } 3,4,5 \text { and } 7 \text { ) }\end{array}$ \\
\hline
\end{tabular}


TABLE 2. Socio-demographic profile of adults living in Indonesia

\begin{tabular}{|c|c|}
\hline Variables or predictors & $n(\%)$ \\
\hline Age in years (mean $\pm S D$ ) & $34.5 \pm 0.95$ \\
\hline $15-24$ & $1235(15.2)$ \\
\hline $25-44$ & $3694(45.3)$ \\
\hline $45-59$ & $1763(21.6)$ \\
\hline 60 and above & $1454(17.8)$ \\
\hline \multicolumn{2}{|l|}{ Gender } \\
\hline Male & $3880(47.6)$ \\
\hline Female & $4266(52.4)$ \\
\hline Household members (mean \pm SD) & $3.62 \pm 0.72$ \\
\hline $1-2$ & $1813(22.3)$ \\
\hline $3-4$ & 4067 (49.9) \\
\hline $5-9$ & $2221(27.3)$ \\
\hline 10 and above & $45(0.6)$ \\
\hline \multicolumn{2}{|l|}{ Place of residence } \\
\hline Urban & $4978(48.8)$ \\
\hline Rural & $5343(51.2)$ \\
\hline \multicolumn{2}{|l|}{ Education level } \\
\hline No formal education & $2088(25.6)$ \\
\hline Less than primary & $2254(27.7)$ \\
\hline Primary completed & $1491(18.3)$ \\
\hline Less than secondary & $1747(21.4)$ \\
\hline Secondary or above & $566(6.9)$ \\
\hline \multicolumn{2}{|l|}{ Working status of the respondent } \\
\hline Employed & $2298(28.2)$ \\
\hline Self-employed & $2971(36.5)$ \\
\hline Student/Unemployed & $2877(35.3)$ \\
\hline \multicolumn{2}{|l|}{ Wealth index (asset quintile) } \\
\hline Lowest & $1348(16.5)$ \\
\hline Low & $1130(13.9)$ \\
\hline Middle & $1595(19.6)$ \\
\hline High & $2510(30.8)$ \\
\hline Highest & 1563.2) \\
\hline
\end{tabular}

determinants [14, 27]. Logistic regressions for multivariate analyses were applied to major factors that substantially explain CTS exposure in four settings [14, 27, 35]. Four binary logistic regression models were utilized separately for four different settings (model A, model B, model C, and model D). Finally, binary logistic regression truly found the impact of independent variables on the dependent variable with odds ratios and categorical interpretations.

$$
\mathrm{P}_{\mathrm{r}}\left(\mathrm{Y}_{\mathrm{i}}=1\right)=\frac{\exp \left(\mathrm{X}_{\mathrm{i}} \beta\right)}{1+\exp \left(\mathrm{X}_{\mathrm{i}} \beta\right)}
$$

Here, is a binary variable that takes a value of ' 1 ' if the respondent is CTS and ' 0 ' otherwise; is a vector of independent variables and is a vector of unknown parameters. The estimated form of the regression model is:

$$
\ln \left[\frac{\mathrm{p}_{\mathrm{i}}}{1-\mathrm{p}_{\mathrm{i}}}\right]=\beta_{0}+\beta_{1} \mathrm{X}_{1}+\ldots+\beta_{\mathrm{k}} X_{k}
$$

The odds ratio (OR) in favor of together with its $95 \%$ confidence interval (CI) are computed for $\mathrm{X}_{1}, \mathrm{X}_{2}, \ldots, \mathrm{X}_{\mathrm{k}}$ to indicate how many times the particular group is more likely to be exposed to CTS compared to the reference group.

\section{RESULTS}

\section{Profile of the respondents}

Basic information about the respondents is provided in Table 2 . Their average age was 34 years, more than $45 \%$ were $25-44$, and roughly $20 \%$ were $45-59$. The male-female ratio was $47.6 \%$ and $52.4 \%$ respectively. About $50 \%$ of respondents had a family of 3-4 members and the average family size was 3 persons. Respondents' residence ratio was $51.2 \%$ rural vs. $48.8 \%$ urban. No formal education was attained by $25.6 \%$ of the respondents and $27.7 \%$ of them had less than primary education. Only $18.3 \%$ of the adults had completed the primary level of education, $21.4 \%$ somewhat less than the secondary level, and $6.9 \%$ of adults had completed secondary or higher education. About $50 \%$ of respondents belonged to the highest two wealth quintiles, whereas $30 \%$ were from the lowest two. While $28.2 \%$ of the adults were employed, $36.5 \%$ were self-employed, and the rest were unemployed or students.

\section{Factors associated with current tobacco smoking exposure}

Table 3 shows the association of several indicators, including socio-demographic factors, health knowledge, perception, and attitude about smoking, with the prevalence of CTS exposure in different settings (model A: male, model B: female, model C: rural, and model $\mathrm{D}$ : urban). In bivariate analysis, age, gender, place of residences, education level, general and specific knowledge of CTS exposure as well as attitudes to CTS of respondents at home and their working status, were significantly ( $p 0.05)$ associated with all of the four models. Perceptions of smoking restrictions in workplaces in model $\mathrm{B}$ as well as, the number of household members in model C and model $\mathrm{D}$, were not statistically associated $(p>0.05)$ with CTS exposure. For model A, all age groups had almost the same distribution with CTS exposure, nearly $50 \%$ or above, whereas, for model B, all age groups had the same distribution of CTS exposure, but this was very modest.

Similarly, both rural and urban adults had almost the same distributional pattern with different age groups and CTS. Adults were more at risk of CTS where the number of household members was 3 to 4 in model A and C, 
TABLE 3. CTS exposure in different settings by selected variables

\begin{tabular}{|c|c|c|c|c|c|c|c|c|}
\hline \multirow[t]{2}{*}{ Variable } & \multicolumn{2}{|c|}{ Model A (male) } & \multicolumn{2}{|c|}{ Model B (female) } & \multicolumn{2}{|c|}{ Model C (rural) } & \multicolumn{2}{|c|}{ Model D (urban) } \\
\hline & Yes $\%$ & $\chi^{2}(p)$ & Yes $\%$ & $\chi^{2}(p)$ & Yes $\%$ & $\chi^{2}(p)$ & Yes $\%$ & $\chi^{2}(p)$ \\
\hline \multicolumn{9}{|l|}{ Age (in years) } \\
\hline $15-24$ & 45.4 & \multirow{4}{*}{$\begin{array}{c}172.18 \\
(<0.000)\end{array}$} & 0.6 & \multirow{4}{*}{$\begin{array}{c}70.81 \\
(<0.000)\end{array}$} & 25.3 & \multirow{4}{*}{$\begin{array}{c}42.62 \\
(<0.000)\end{array}$} & 19.1 & \multirow{4}{*}{$\begin{array}{c}60.07 \\
(<0.000)\end{array}$} \\
\hline $25-44$ & 73.0 & & 2.2 & & 38.4 & & 33.9 & \\
\hline $45-59$ & 73.8 & & 5.4 & & 40.9 & & 36.4 & \\
\hline 60 and above & 68.6 & & 7.6 & & 38.0 & & 31.8 & \\
\hline \multicolumn{9}{|c|}{ No. of household members } \\
\hline $1-2$ & 67.5 & \multirow{4}{*}{$\begin{array}{c}11.46 \\
(<0.009)\end{array}$} & 6.7 & \multirow{4}{*}{$\begin{array}{c}42.24 \\
(<0.000)\end{array}$} & 34.9 & \multirow{4}{*}{$\begin{array}{c}5.08 \\
(0.166)\end{array}$} & 29.1 & \multirow{4}{*}{$\begin{array}{c}5.40 \\
(0.144)\end{array}$} \\
\hline $3-4$ & 70.1 & & 2.2 & & 38.5 & & 33.3 & \\
\hline $5-9$ & 65.6 & & 3.4 & & 36.3 & & 30.6 & \\
\hline 10 and above & 48.0 & & 10.0 & & 27.3 & & 34.8 & \\
\hline \multicolumn{9}{|l|}{ Residence } \\
\hline Urban & 62.5 & \multirow{2}{*}{$\begin{array}{c}57.02 \\
(<0.000)\end{array}$} & 3.0 & \multirow{2}{*}{$\begin{array}{c}5.47 \\
(<0.019)\end{array}$} & \multirow[t]{2}{*}{-} & \multirow[t]{2}{*}{-} & - & - \\
\hline Rural & 73.8 & & 4.3 & & & & & \\
\hline Gender & & & & & & & & \\
\hline Male & - & - & - & - & 73.8 & 2151.06 & 62.5 & 1627.61 \\
\hline Female & & & & & 4.3 & $(<0.000)$ & 3.0 & $(<0.000)$ \\
\hline Education level & & & & & & & & \\
\hline No formal education & 81.5 & 204.97 & 7.1 & 64.05 & 39.7 & 23.74 & 31.7 & 19.81 \\
\hline Less than primary & 75.3 & $(<0.000)$ & 3.2 & $(<0.000)$ & 37.1 & $(<0.000)$ & 36.5 & $(<0.001)$ \\
\hline Primary completed & 62.0 & & 1.0 & & 32.0 & & 29.8 & \\
\hline Less than secondary & 60.7 & & 2.0 & & 39.6 & & 31.9 & \\
\hline Secondary or above & 44.9 & & 2.2 & & 23.7 & & 24.8 & \\
\hline Wealth index & & & & & & & & \\
\hline Lowest ( $1^{\text {st }}$ quintile) & 82.2 & 188.60 & 5.5 & 20.91 & 37.2 & 13.12 & 31.9 & 54.23 \\
\hline Low ( ${ }^{\text {nd }}$ quintile) & 76.3 & $(<0.000)$ & 4.9 & $(<0.000)$ & 35.7 & $(<0.011)$ & 36.6 & $(<0.001)$ \\
\hline Middle ( $3^{\text {rd }}$ quintile) & 74.3 & & 3.6 & & 37.9 & & 40.6 & \\
\hline High ( $4^{\text {th }}$ quintile) & 66.1 & & 3.1 & & 39.3 & & 31.9 & \\
\hline Highest ( $5^{\text {th }}$ quintile) & 50.6 & & 1.6 & & 28.8 & & 25.0 & \\
\hline Working status & & & & & & & & \\
\hline Employed & 69.2 & 232.10 & 2.8 & 13.32 & 49.6 & 558.86 & 43.3 & 527.57 \\
\hline Self-employed & 75.8 & $(<0.000)$ & 5.4 & $(<0.001)$ & 48.2 & $(<0.000)$ & 49.0 & $(<0.000)$ \\
\hline Student/Unemployed & 41.9 & & 3.1 & & 10.1 & & 11.4 & \\
\hline Smoking policy at home & & & & & & & & \\
\hline Allowed & 74.4 & 218.31 & 4.0 & 18.78 & 39.9 & 62.98 & 38.5 & 104.54 \\
\hline Not allowed & 47.9 & $(<0.000)$ & 1.7 & $(<0.000)$ & 22.7 & $(<0.000)$ & 21.8 & $(<0.000)$ \\
\hline No rules & 73.8 & & 5.0 & & 38.9 & & 33.4 & \\
\hline Smoking policy at work & & & & & & & & \\
\hline Allowed & 62.7 & 44.14 & 2.7 & 1.76 & 47.7 & 10.83 & 44.5 & 43.78 \\
\hline Not allowed & 55.3 & $(<0.000)$ & 2.5 & $(0.416)$ & 29.7 & $(<0.004)$ & 33.6 & $(<0.000)$ \\
\hline No rules & 70.7 & & 3.8 & & 36.7 & & 29.3 & \\
\hline General health knowled & & & & & & & & \\
\hline Yes & 65.1 & 94.90 & 2.8 & 42.30 & 34.8 & 36.23 & 30.2 & 28.69 \\
\hline No & 80.2 & $(<0.000)$ & 8.0 & $(<0.000)$ & 46.3 & $(<0.000)$ & 42.0 & $(<0.000)$ \\
\hline Specific health knowled & & & & & & & & \\
\hline No knowledge & 87.0 & 164.47 & 7.4 & 33.75 & 44.3 & 23.46 & 38.1 & 55.89 \\
\hline Some knowledge & 73.7 & $(<0.000)$ & 3.9 & $(<0.000)$ & 37.5 & $(<0.000)$ & 38.2 & $(<0.000)$ \\
\hline Good knowledge & 59.4 & & 2.4 & & 33.6 & & 27.0 & \\
\hline
\end{tabular}

Pearson $\chi^{2}$-square test, Model A-CTS exposed at male adults, Model B - CTS exposed at female adults, Model C-CTS exposed at rural adults and Model D-CTS exposed at urban adults. 
along with more than 10 members in model B and D. Rural males and females were more exposed to CTS compared to their urban counterparts. Males showed higher CTS rates in comparison with females in both rural and urban models. All the models had the same patterns for the variable education level, indicating that Indonesian adults who received no formal education were more exposed to CTS, but comparatively, males were more addicted to CTS in each level of education than females. Model A and B both showed similar patterns in wealth quintiles where $1^{\text {st }}$ quintile adults were more likely to be CTS exposed, but rural adults in the $3^{\text {rd }}$ and $4^{\text {th }}$ quintiles and urban adults in the $3^{\text {rd }}$ quintile had higher CTS exposure. All the models except B had the same patterns for the variable working status, indicating that employed and self-employed adults were more exposed to CTS, whereas, student and unemployed adults were more affected in model B. "Smoking allowed" and "no rules at home" policies corresponded to a pattern of excessive CTS exposure compared to a "not allowed" policy. Likewise, in workplaces, CTS exposure was more common where there were "no rules" for smoking. Most respondents were subject to "no rules" and "allowed" policies. Respondents with health knowledge about TS showed comparatively less CTS than those with no knowledge in all the models.

\section{Binary logistic regression analysis}

For model A (male group), the results show that males aged 25-44 years had significantly higher odds (OR $=1.56,95 \% \mathrm{CI}=1.17-2.06)$ and those $45-59$ had significantly lower odds $(\mathrm{OR}=0.69,95 \% \mathrm{CI}=0.58-0.82)$ of CTS exposure compared to their counterparts 15-24 years old. For example, a male between 25 and 44 years old was 1.56 times more likely to present CTS exposure compared to those aged 15-24 years. Approximately 46\%, 49\%, 53\%, and $56 \%$ of respondents with education levels less than primary, primary, less than secondary, and secondary and above, respectively, had lower odds to be exposed than respondents with no formal education.

Similarly, low to high wealth quintiles are significantly (associated with CTS exposure and there is less likelihood $(\mathrm{OR}=0.46,95 \% \mathrm{CI}=0.33-0.63 ; \mathrm{OR}=0.61,95 \% \mathrm{CI}=$ $0.45-0.82$; OR $=0.61,95 \% \mathrm{CI}=0.47-0.79)$ to be exposed at the model A compared to the reference category of lowest wealth index category (Table 4). Approach to CTS exposure at home was significantly associated with no rules, there was $(\mathrm{OR}=2.32,95 \% \mathrm{CI}=1.87-2.87)$ a higher chance of CTS exposure for male adults who were allowed to smoke in comparison with those who were not allowed. General and specific health knowledge of TS had a substantial influence on CTS exposure in model A. For instance, male adults had 1.48 times higher chance to be exposed to CTS compared to those who had no general health knowledge. Moreover, adults with no knowledge had a higher chance to be exposed compared to adults with some knowledge $(\mathrm{OR}=0.45,95 \% \mathrm{CI}=0.30-0.67)$ and good knowledge $(\mathrm{OR}=0.69,95 \% \mathrm{CI}=0.58-0.82)$. Again, self-employed $(\mathrm{OR}=0.31,95 \% \mathrm{CI}=0.23-0.40)$ and students/unemployed $(\mathrm{OR}=0.38,95 \% \mathrm{CI}=0.29-0.48$ ) male adults are less likely to be exposed to CTS compared to employed male adults.

For model B (female group), female adults aged 25-44 years $(\mathrm{OR}=6.44,95 \% \mathrm{CI}=2.19-18.95)$ and $45-59$ years $(\mathrm{OR}=2.04,95 \% \mathrm{CI}=1.25-3.33)$ had higher risk of exposure compared to their counterparts aged 15-24 years. The two older groups were significantly associated with CTS. Households with more members significantly increased the odds of CTS exposure among females. For example, if the households had 3-4, 5-9, and 10 or more persons, there were 2.49-, 4.94-, and 3.01-times greater possibilities of CTS exposure, respectively, compared to the reference category (1-2 persons living in a household). In the female group, the attitude to CTS exposure at home affected outcomes. No rules at home yielded $(\mathrm{OR}=2.53,95 \% \mathrm{CI}=1.45-4.41)$ higher chances of CTS exposure compared to smoking allowed at home. However, no general knowledge of CTS exposure doubled the chances of exposure among female adults.

For model C (rural), adults aged 45-59 years had considerably higher odds $(\mathrm{OR}=1.72,95 \% \mathrm{CI}=1.17-2.51)$ of CTS exposure compared to the reference category (15-24 years). Females were $99 \%$ less likely to be exposed than males in rural areas. Similarly, adults in rural areas with an education level of less than primary, primary, and secondary and above had, respectively, 36\%, 48\%, and $45 \%$ lower odds of exposure than adults with no formal education. Rural people with a lower wealth index had higher chances to be exposed.

In rural communities, there was a major effect on CTS exposure for respondents who had general and specific health knowledge. For instance, people had 1.47 times higher likelihood to be exposed with no general health knowledge of CTS in rural areas in comparison to people with some knowledge ( $\mathrm{OR}=0.53,95 \%$ $\mathrm{CI}=0.33-0.82)$. Perspective to CTS in rural places was significantly associated with exposure level. Adults with a "no rules" policy at home had 2.89 times higher risk of CTS exposure in rural areas compared to respondents who were allowed. Likewise, at workplaces, a "no rules" policy yielded a 1.59 times greater chance of CTS exposure than "allowed" TS in rural areas. Again, working status of adults in rural areas was considerably related to the lower exposure level. For example, self-employed $(\mathrm{OR}=0.29$, $95 \% \mathrm{CI}=0.20-0.40)$ and student/unemployed $(\mathrm{OR}=0.36$, $95 \% \mathrm{CI}=0.26-0.49)$ rural adults had a lower likelihood to be exposed to CTS compared to the employed.

For model D (urban), adults 25-44 years old had a 2.25 times higher chance of CTS exposure than the reference category (15-24 years) in urban areas. Similarly, females were $86 \%$ less likely to be exposed to urban places than males. There was a $50 \%, 52 \%, 57 \%$, and $62 \%$ 
TABLE 4. Parameter estimates of the logistic regression for all the covariates for several models

\begin{tabular}{|c|c|c|c|c|}
\hline \multirow[t]{2}{*}{ Variables } & Model A (male) & Model B (female) & Model C (rural) & Model D (urban) \\
\hline & OR $(95 \% \mathrm{CI})$ & OR $(95 \% \mathrm{CI})$ & OR $(95 \% \mathrm{CI})$ & OR $(95 \% \mathrm{CI})$ \\
\hline \multicolumn{5}{|l|}{ Age (in years) } \\
\hline 15-24 (Ref) & - & - & - & - \\
\hline $25-44$ & $1.56(1.17-2.06)^{* * * *}$ & $6.44(2.19-18.95)^{* * *}$ & $1.72(1.17-2.51)^{* * * *}$ & $2.25(1.56-3.25)^{* * * *}$ \\
\hline $45-59$ & $0.71(0.56-0.90)^{* * *}$ & $2.04(1.25-3.33)^{* * *}$ & $0.94(0.69-1.27)$ & $0.79(0.60-1.06)$ \\
\hline 60 and above & $0.78(0.60-1.00)$ & $1.23(0.80-1.87)$ & $0.88(0.64-1.19)$ & $0.85(0.61-1.19)$ \\
\hline \multicolumn{5}{|l|}{ No. of household members } \\
\hline $1-2$ (Ref) & - & - & - & - \\
\hline $3-4$ & $0.54(0.22-1.27)$ & $2.49(0.52-11.85)$ & $0.35(0.10-1.17)$ & $1.27(0.41-3.92)$ \\
\hline $5-9$ & $0.45(0.19-1.03)$ & $4.94(1.03-23.62)^{* * *}$ & $0.41(0.12-1.34)$ & $1.02(0.34-3.10)$ \\
\hline 10 and above & $0.44(0.18-1.03)$ & $3.01(0.62-14.52)$ & $0.37(0.11-1.23)$ & $0.95(0.31-2.89)$ \\
\hline \multicolumn{5}{|l|}{ Residence } \\
\hline Urban (Ref) & - & - & - & - \\
\hline Rural & $0.95(0.79-1.12)$ & $0.96(0.66-1.38)$ & - & - \\
\hline \multicolumn{5}{|l|}{ Gender } \\
\hline Male (Ref) & - & - & - & - \\
\hline Female & - & - & $0.01(0.01-0.02)^{* * *}$ & $0.14(0.12-0.17)^{* * * *}$ \\
\hline \multicolumn{5}{|l|}{ Education level } \\
\hline No formal education (Ref) & - & - & - & - \\
\hline Less than primary & $0.46(0.31-0.66)^{* * *}$ & $0.89(0.31-2.51)$ & $0.36(0.19-0.65)^{* * *}$ & $0.50(0.31-0.79)^{* * *}$ \\
\hline Primary completed & $0.49(0.35-0.68)^{* * *}$ & $1.23(0.44-3.45)$ & $0.48(0.27-0.85)^{* * *}$ & $0.52(0.34-0.76)^{* * * *}$ \\
\hline Less than secondary & $0.53(0.38-0.73)^{* * *}$ & $2.40(0.74-7.73)$ & $0.56(0.31-1.00)$ & $0.57(0.38-0.83)^{* * * *}$ \\
\hline Secondary or above & $0.56(0.41-0.75)^{* * *}$ & $1.22(0.44-3.36)$ & $0.45(0.25-0.80)^{* * * *}$ & $0.62(0.44-0.85)^{* * *}$ \\
\hline \multicolumn{5}{|l|}{ Wealth index } \\
\hline Lowest (Ref) & - & - & - & - \\
\hline Low & $0.46(0.33-0.63)^{* * *}$ & $0.83(0.38-1.80)$ & $0.52(0.34-0.80)^{* * *}$ & $0.54(0.34-0.85)^{* * *}$ \\
\hline Middle & $0.61(0.45-0.82)^{* * *}$ & $0.56(0.26-1.18)$ & $0.62(0.40-0.94)^{* * *}$ & $0.49(0.33-0.72)^{* * *}$ \\
\hline High & $0.61(0.47-0.79)^{* * *}$ & $0.64(0.30-1.33)$ & $0.69(0.45-1.03)$ & $0.47(0.34-0.65)^{* * * *}$ \\
\hline Highest & $0.82(0.65-1.01)$ & $0.62(0.31-1.24)$ & $0.61(0.41-0.90)^{* * *}$ & $0.91(0.71-1.16)$ \\
\hline \multicolumn{5}{|l|}{ Smoking policy at home } \\
\hline Allowed (Ref) & - & - & - & - \\
\hline Not allowed & $0.94(0.78-1.13)$ & $1.32(0.91-1.89)$ & $1.02(0.82-1.27)$ & $0.91(0.70-1.18)$ \\
\hline No rules & $2.32(1.87-2.87)^{* * *}$ & $2.53(1.45-4.41)^{* * *}$ & $2.89(2.13-3.92)^{* * *}$ & $1.98(1.49-2.60)^{* * * *}$ \\
\hline \multicolumn{5}{|l|}{ General health knowledge } \\
\hline Yes (Ref) & - & - & - & - \\
\hline No & $1.48(1.08-2.04)^{* * *}$ & $2.00(1.15-3.43)^{* * *}$ & $1.47(1.02-2.13)^{* * *}$ & $1.73(1.15-2.60)^{* * *}$ \\
\hline \multicolumn{5}{|l|}{ Specific health knowledge } \\
\hline No knowledge (Ref) & - & - & - & - \\
\hline Some knowledge & $0.45(0.30-0.67)^{* * *}$ & $1.36(0.69-2.67)$ & $0.53(0.33-0.82)^{* * *}$ & $0.74(0.44-1.21)$ \\
\hline Good knowledge & $0.69(0.58-0.82)^{* * *}$ & $1.05(0.68-1.61)$ & $0.82(0.65-1.02)$ & $0.65(0.52-0.81)^{* * * *}$ \\
\hline \multicolumn{5}{|l|}{ Smoking policy at workplace } \\
\hline Allowed (Ref) & - & - & - & - \\
\hline Not allowed & $1.21(0.93-1.55)$ & $0.87(0.32-2.34)$ & $1.33(0.85-2.05)$ & $1.01(0.74-1.36)$ \\
\hline No rules & $1.28(0.97-1.69)$ & $0.68(0.26-1.73)$ & $1.59(0.85-2.97)^{* * *}$ & $1.03(0.75-1.39)$ \\
\hline \multicolumn{5}{|l|}{ Work status } \\
\hline Employed & - & - & - & - \\
\hline Self-employed & $0.31(0.23-0.40)^{* * *}$ & $1.19(0.66-2.10)$ & $0.29(0.20-0.40)^{* * *}$ & $0.56(0.41-0.76)^{* * *}$ \\
\hline Student/Unemployed & $0.38(0.29-0.48)^{* * *}$ & $0.72(0.49-1.04)$ & $0.36(0.26-0.49)^{* * *}$ & $0.56(0.41-0.76)^{* * *}$ \\
\hline
\end{tabular}

Ref - reference category, OR - odds ratio, $\mathrm{Cl}$ - confidence interval, $p<0.05^{* * * *}$. Model $A-C T S$ exposed at male adults, Model $B-C T S$ exposed at female adults, Model C - CTS exposed at rural adults and Model D - CTS exposed at urban adults 
lower chance of exposure to CTS with the education level of less than primary, primary, less than secondary, and secondary or above, respectively, compared to people who had no formal education in urban areas. Respondents who lived with the lowest wealth index had a higher likelihood to be exposed. For instance, people living in the lowest wealth index had $47 \%$ to $49 \%$ more probability to be exposed than people living in middle to higher wealth quintiles, respectively, in urban areas.

Approaches to CTS at home were associated with higher chances of exposure in urban areas. A "no rules" policy at home yielded $(\mathrm{OR}=1.98,95 \% \mathrm{CI}=1.49-2.60)$ higher odds of CTS exposure in urban places compared to "smoking allowed" at home. General and specific health knowledge had a significant influence on the CTS exposure. For example, adults who had no general knowledge about TS in urban areas had 1.73 times higher likelihood to be exposed to CTS. Moreover, respondents who had no general knowledge had higher odds of CTS exposure than adults with good knowledge $(\mathrm{OR}=0.65,95 \% \mathrm{CI}=0.52-0.81)$. The working status of adults in urban regions was significantly related to lower exposure level. For example, self-employed and student/ unemployed adults $(\mathrm{OR}=0.56,95 \% \mathrm{CI}=0.41-0.476)$ had a lower likelihood of exposure to CTS compared to employed adults.

\section{DISCUSSION}

More than $60 \%$ of Indonesian adults were CTS exposed, irrespective of sex, in both rural and urban areas. Among adults, CTS exposure was higher in males than females aged 25-59 years, in both rural and urban areas, and this result was consistent with other related studies [8, 12, 36, 37]. Higher exposure to CTS was reported among Indonesian adults aged 45-59 years, compared to other age groups in both areas $[8,12,38,39]$. In line with this study, South-East Asian countries, for example, India and Bangladesh, showed an increasing incidence of tobacco consumption and users tended to be middle-aged people $[12,36,37]$. Households consisting of a large number of family members exhibited more risk of CTS exposure for female groups, whereas more than five members in a household showed less risk for male groups. Consistent results have been reported by several studies conducted in China and Bangladesh [40, 41].

As in other studies $[12,42,43]$ place of residence also showed significant association with CTS exposure. For example, urban respondents showed remarkably less risk of exposure to CTS than their rural counterparts, and some researchers have suggested that this may be caused by a lack of awareness about the harmful effects of TS $[8,14,44]$. In both rural and urban areas, female adults had a lower chance of exposure than male adults, and this may be caused by gender discrimination in hiring for particular jobs $[12,14,45]$. Females were reported to be less prevalent and appreciated in the job sectors, as they are mostly housewives and self-employed, especially in the South-Asian region [5, 45-47]. Some other research performed in South-East Asian countries, like China, India, Bangladesh, etc., have reported similar results $[16,37,39]$. The differences in the level of CTS exposure in rural-urban areas for both male and female groups were insignificant, whereas a contrary relationship was found in different articles [12, 43, 48].

The level of education has a higher influence on TS exposure in different selected models of our study, which has similarities to other relevant studies conducted in India, Bangladesh, Nepal, and China [12, 42-44]. Higher education has a positive impact on creating a smoke-free environment in rural-urban areas [46, 49] which is helpful for both smokers and non-smokers who do not know the health risks of TS [11]. In line with the other findings, this study showed that Indonesian male respondents with higher education have significantly lower chances to be exposed to TS than respondents with no education in both rural and urban areas [11], though this result varied in the case of females [42]. Indonesian adults who come from higher wealth quintiles have a lower risk of TS exposure in all selected models, which has similarities to other studies [11, 14, 44, 50-52]. That could be due to economic status, consciousness about health, and environmental policy. Adults who are working professionally, are less likely to become addicted to tobacco compared to unemployed adults, except for businesswomen. This result is also supported by some other studies [11, 44].

Various results were reported about general and specific health knowledge of TS exposure in Indonesia. The population with low specific health knowledge has a higher rate of smoking and thus a higher likelihood of exposure to TS $[39,53]$. For example, males who have either some knowledge or good knowledge had a lower chance to be exposed to CTS compared to males without any knowledge. In contrast to this result, Indian adult males with some knowledge or good knowledge showed a higher risk of exposure to TS, maybe due to socioeconomic and cultural deviations [14, 42, 54-56]. We found that policies regarding smoking at home are significantly associated with CTS exposure. A "not allowed" policy yields lower exposure, compared to a "no rule" policy. This result and consistent research suggest that consciousness about the health risks of TS was positively related to creating smoking-free zones [14, 42, 54-56]. To improve the efficacy of current public health policies as well as to develop the targeted strategies, surveillance of the tobacco epidemic is required $[12,14,36,42]$.

It was reported that general and specific health knowledge about TS is significantly related to exposure in both rural and urban places. Smoking restrictions and quitting were potentially associated with proper knowledge of health risks and attitudes towards smoking [42, 54-56]. Also, attitudes to TS exposure in rural areas are a greater risk than in urban areas. 
There are several strengths and limitations to this study. Not all the associated risk factors (such as the number of smoked versus smokeless tobacco users, smoking frequency, media exposure, etc.) were included on account of missing values in the dataset. The GATS in Indonesia incorporated all eligible populations of men and women, including non-citizens (tourists) who were visiting only briefly, aged 15 years and above. The major strength of this study is that it permits us to reach the relevant perception because it used a nationally representative sample survey. Furthermore, it may be an under-representation of the entire tobacco use prevalence in the Indonesian population because it reported only on the current use of tobacco. However, this study does provide social determining factors that may inform future interveners to establish smoke-free zones.

\section{CONCLUSIONS}

This study explored current tobacco smoking among Indonesian adults based on gender and place of residence. Male adults always show more inclination towards tobacco smoking than females, and rural people have a higher risk of exposure to CTS than their urban counterparts. People with less education and wealth, along with working people, are more likely to use tobacco. Indonesian adults have limited knowledge about smoking and the diseases it generates. The nation's current laws and policies to protect people from CTS exposure are insufficient. Most of the benchmark policies are partial and inadequate, failing to provide complete bans on smoking in rural and urban places. Policymakers and the tobacco control community endorse constraints with rigorous enforcement, which have been shown to have a notable effect on decreasing tobacco use. To reduce CTS exposure, effective public education, media advocacy, and communication can play a vital role in increasing awareness of the harmfulness of TS. Government and non-government institutions should together initiate activities to make people aware of smoking, both indoors and outdoors. Such an effort would help Indonesia achieve its sustainable development goals.

\section{DISCLOSURE}

The authors report no conflict of interest.

\section{References}

1. World Health Organization. WHO report on the global tobacco epidemic 2019: Offer help to quit tobacco use. World Health Organization, 2019. Available from: https://escholarship.org/ content/qt1g16k8b9/qt1g16k8b9.pdf (accessed: 14 November 2020)

2. World Health Organization. WHO global report on trends in prevalence of tobacco use 2000-2025. World Health Organization, 2019. Available from: https://apps.who.int/iris/bitstream/hand le/10665/330221/9789240000032-eng.pdf (accessed: 14 November 2020).
3. Jha P, Peto R, Zatonski W, et al. Social inequalities in male mortality, and in male mortality from smoking: indirect estimation from national death rates in England and Wales, Poland, and North America. Lancet 2006; 368(9533): 367-370.

4. Shrivastava SR, Shrivastava PS. Strengthening measures to quit tobacco and control the tobacco epidemic globally: World Health Organization. Journal of the Scientific Society 2019; 46(3): 110.

5. World Health Organization. WHO report on the global tobacco epidemic, 2011: Warning about the dangers of tobacco: Executive summary. Geneva: World Health Organization; 2011. Available from: https://apps.who.int/iris/bitstream/ handle/10665/70680/WHO_NMH_TFI_11.3_rus.pdf (accessed: 14 November 2020).

6. Mathers CD, Loncar D. Projections of global mortality and burden of disease from 2002 to 2030. PLoS Med 2006; 3(11): e442.

7. Edwin VA. Habit of smoking family members at home to successful smoking cessation in Indonesia. KnE Life Sciences 2018; 74-83. Available from: https://doi.org/10.18502/kls.v4i1.1368 (accessed: 14 November 2020).

8. World Health Organization. Global adult tobacco survey: Indonesia report 2011. Available from: https://apps.who.int/ iris/handle/10665/205137 (accessed: 14 November 2020).

9. World Health Organization. World health statistics 2016: monitoring health for SDGs sustainable development goals. World Health Organization; 2016. Available from: https://www. who.int/gho/publications/world_health_statistics/2016/en/ (accessed: 14 November 2020).

10. Sifaki-Pistolla D, Lionis C, Georgoulias V, et al. Lung cancer and tobacco smoking in Crete, Greece: reflections from a population-based cancer registry from 1992 to 2013. Tob Induc Dis 2017; 15: 6 .

11. Swatan JP, Sulistiawati S, Karimah A. Determinants of tobacco smoking addiction in rural Indonesian communities. J Environ Public Health 2020; 2020: 7654360.

12. Palipudi KM, Gupta PC, Sinha DN, et al. Social determinants of health and tobacco use in thirteen low- and middle-income countries: evidence from Global Adult Tobacco Survey. PLoS One 2012; 7(3): e33466.

13. Ekpu VU, Brown AK. The economic impact of smoking and of reducing smoking prevalence: review of evidence. Tob Use Insights 2015; 8: 1-35.

14. Kabir MA, Hossain MM, Duty FA. Patterns, prevalence and determinants of environmental tobacco smoke exposure among adults in Bangladesh. Addict Behav Rep 2018; 8: 113-121.

15. California Environmental Protection Agency. Air Resources Board. Proposed Identification of Environmental Tobacco Smoke as a Toxic Air Contaminant... as Approved by the Scientific Review Panel on June 24, 2005: Health effects. California Environmental Protection Agency, Air Resources Board; 2005. Available from: https://ww2.arb.ca.gov/sites/default/files/classic//toxics/id/summary/etspt_a.pdf (accessed: 14 November 2020).

16. Mbulo L, Palipudi KM, Andes L, et al. Secondhand smoke exposure at home among one billion children in 21 countries: findings from the Global Adult Tobacco Survey (GATS). Tob Control 2016; 25(e2): e95-e100. 
17. Al-Sadat N, Misau AY, Zarihah Z, et al. Adolescent tobacco use and health in Southeast Asia. Asia Pac J Public Health 2010; 22(3 Suppl): 175S-180S.

18. Owonaro PA, Eniojukan JF. Cigarette smoking practices, perceptions and awareness of government policies among pharmacy students in Niger Delta University in South-South Nigeria. UK J Pharm Biosci 2015; 3(5): 20-29.

19. Brown SL, Teufel JA, Birch DA. Early adolescents' perceptions of health and health literacy. J School Health 2007; 77(1): 7-15.

20. United Nations Conference on Trade and Development (UNCTAD). Economic Development in Africa Report 2018: Migration for structural transformation. Available from: https:// unctad.org/en/pages/PublicationWebflyer.aspx?publicationid $=2118$ (accessed: 14 November 2020)

21. Handayani N, Husodo BT, Cahyo K, et al. Examining the smoking levels of junior high school students in Semarang City, Indonesia. Journal of Public Health for Tropical and Coastal Region 2020; 3(1): 1-8.

22. World Health Organization. WHO report on the global tobacco epidemic 2019: offer help to quit tobacco use. Geneva: Switzerland. Available from: https://escholarship.org/content/ qt1g16k8b9/qt1g16k8b9.pdf (accessed: 14 November 2020).

23. Anderson CL, Becher H, Winkler V. Tobacco control progress in low- and middle-income countries in comparison to high income countries. Int J Environ Res Public Health 2016; 13 (10): 1039.

24. Filippini G, Maisonneuve P, McCredie M, et al. Relation of childhood brain tumors to exposure of parents and children to tobacco smoke: the Search international case-control study. Int J Cancer 2002; 100(2): 206-213.

25. Binkin N, Perra A, Aprile V, et al. Effects of a generalised ban on smoking in bars and restaurants, Italy. Int J Tuberc Lung Dis 2007; 11(5): 522-527.

26. Riahi M, Mohammadi A, Rohani H, et al. Dataset on the prevalence of tobacco smoking in men and women of selected countries whit difference human development. Data Brief 2018; 18 506-511.

27. Kusumawardani N, Tarigan I, Suparmi EA, Schlotheuber A. Socio-economic, demographic and geographic correlates of cigarette smoking among Indonesian adolescents: results from the 2013 Indonesian Basic Health Research (RISKESDAS) survey. Glob Health Action 2018; 11(Suppl 1): 1467605.

28. Pampel F. Divergent patterns of smoking across high-income nations. In: International differences in mortality at older ages: dimensions and sources. Washington: The National Academic Press; 2010, 132-163.

29. World Health Organization, Research for International Tobacco Control. WHO report on the global tobacco epidemic, 2008: the MPOWER package. World Health Organization. Available from: https://www.who.int/tobacco/mpower/mpower_report_ tobacco_crisis_2008.pdf (accessed: 14 November 2020).

30. Jha V, Garcia-Garcia G, Iseki K, et al. Chronic kidney disease: global dimension and perspectives. Lancet 2013; 382(9888): 260-272.

31. Shapiro H (ed.). No Fire, No Smoke: Global State of Tobacco Harm Reduction 2018. Knowledge-Action-Change; 2018. Available from: https:/www.smokefreeworld.org/wp-content/
uploads/2019/06/Global-State-of-Tobacco-Harm-Reduction-2018.pdf (accessed: 14 November 2020).

32. Nagler MN. The search for a nonviolent future: a promise of peace for ourselves, our families, and our world. New World Library; 2010.

33. Kosen S. The health burden of tobacco use. In: The Tobacco Sourcebook. Republic of Indonesia: Ministry of Health; 2004. Available from: https://extranet.who.int/kobe_centre/sites/ default/files/tobaccosourcebook.pdf (accessed: 14 November 2020).

34. GATS (Global Adult Tobacco Survey) Fact sheet Indonesia 2011. Available from: https://www.who.int/tobacco/surveillance/ survey/gats/indonesia_factsheet_8_february_2012.pdf?ua=1 (accessed: 14 November 2020).

35. Chan YH. Biostatistics 202: logistic regression analysis. Singapore Med J 2004; 45(4): 149-153.

36. Rachiotis G, Siziya S, Muula AS, et al. Determinants of exposure to environmental tobacco smoke (ETS) among non-smoking adolescents (aged 11-17 years old) in Greece: results from the 2004-2005 GYTS Study. Int J Environ Res Public Health 2010; 7(1): 284-290.

37. Orlan E, Duncan K, Amtha R, Parascandola M. Characteristics of current betel quid/chewing tobacco users, smokers and dual users in Indonesia: an analysis of GATS 2011 data. Substance Use and Misuse 2020; 55 (9): 1509-1512.

38. Thompson ME, Fong GT, Hammond D, et al. Methods of the International Tobacco Control (ITC) four country survey. Tobacco Control 2006; 15 (Suppl 3): iii12-18.

39. Abdullah AS, Hittchman SC, Driezen P, et al. Socioeconomic differences in exposure to tobacco smoke pollution (TSP) in Bangladeshi households with children: findings from the International Tobacco Control (ITC) Bangladesh Survey. Int J Environ Res Public Health 2011; 8(3): 842-860.

40. Hyland A, Higbee C, Travers MJ, et al. Smoke-free homes and smoking cessation and relapse in a longitudinal population of adults. Nicotine Tob Res 2009; 11(6): 614-618.

41. Sims M, Tomkins S, Judge K, et al. Trends in and predictors of second-hand smoke exposure indexed by cotinine in children in England from 1996 to 2006. Addiction 2010; 105(3): 543-553.

42. Abdullah AS, Yang T, Beard J. Predictors of women's attitudes toward World Health Organization framework convention on tobacco control policies in urban China. J Womens Health 2010; 19(5): 903-909.

43. Khan MM, Aklimunnessa K, Kabir MA, Kabir M, Mori M. Tobacco consumption and its association with illicit drug use among men in Bangladesh. Addiction 2006; 101(8): 1178-1186.

44. Khanal V, Adhikari M, Karki S. Social determinants of tobacco consumption among Nepalese men: findings from Nepal Demographic and Health Survey 2011. Harm Reduct J 2013; 10: 40 .

45. Morrow M, Simon B. Tobacco control and gender in south-east Asia. Part II: Singapore and Vietnam. Health Promot Int 2003; 18(4): 373-380.

46. World Health Organization. WHO report on the global tobacco epidemic, 2013: enforcing bans on tobacco advertising, promotion and sponsorship. World Health Organization; 2013. Availa- 
ble from: https://www.who.int/tobacco/global_report/2013/en/ (accessed: 14 November 2020).

47. Richter LK. Exploring theories of female. Leadership in South and Southeast Asia. Pacific Affairs 1990; 63(4): 524-540.

48. Bolte G, Fromme H; GME Study Group. Socioeconomic determinants of children's environmental tobacco smoke exposure and family's home smoking policy. Eur J Public Health 2009; 19(1): 52-58.

49. Öberg M, Jaakkola MS, Woodward A, Peruga A, Prüss-Ustün A. Worldwide burden of disease from exposure to second-hand smoke: a retrospective analysis of data from 192 countries. Lancet 2011; 377(9760): 139-146.

50. Manimunda SP, Benegal V, Sugunan AP, et al. Tobacco use and nicotine dependency in a cross-sectional representative sample of 18,018 individuals in Andaman and Nicobar Islands, India. BMC Public Health 2012; 12: 515.

51. Rani M, Bonu S, Jha P, Nguyen SN, Jamjoum L. Tobacco use in India: prevalence and predictors of smoking and chewing in a national cross sectional household survey. Tob Control 2003; 12(4): e4.

52. Doku D, Darteh EK, Kumi-Kyereme A. Socioeconomic inequalities in cigarette smoking among men: evidence from the 2003 and 2008 Ghana demographic and health surveys. Arch Public Health 2013; 71(1): 9.

53. Nketiah-Amponsah E, Afful-Mensah G, Ampaw S. Determinants of cigarette smoking and smoking intensity among adult males in Ghana. BMC Public Health 2018; 18: 941.

54. Chen YH, Yeh CY, Chen RY, et al. Moving toward people's needs for smoke-free restaurants: before and after a National Promotion Program in Taiwan, 2003-2005. Nicotine Tob Res 2009; 11(5): 503-513.

55. Li X, Buechner JM, Tarwater PM, Muñoz A. A diamond-shaped equiponderant graphical display of the effects of two categorical predictors on continuous outcomes. The American Statistician 2003; 57(3): 193-199.

56. Singh A, Ladusingh L. Prevalence and determinants of tobacco use in India: evidence from recent Global Adult Tobacco Survey data. PLoS One 2014; 9(12): e114073.

\section{AUTHORS' CONTRIBUTIONS}

SK and AR prepared the concept of the paper. SK and TMM analysed data. SK and TMM interpreted data. AR wrote and revised the publication. All authors have given their final approval to the final version of the paper. 